\title{
Research on the Whole Teaching of Vocal Music Course in College Music Performance
}

\author{
Xu Qian \\ Jilin Normal University, Jilin, China 136000
}

Keywords: music performance; vocal music; teaching status; reform research

Abstract: In recent years, with the rapid development of China's higher education, colleges and universities have set up vocal performances. The overall teaching level of vocal music courses in college music performance has an important influence on the development of students' vocal performance and comprehensive quality. However, there are still many problems in the teaching content, methods and methods of vocal performance majors in colleges and universities. In order to cultivate high-quality music talents, vocal music teaching should be reformed. This paper mainly analyzes the current situation of vocal music teaching in music performance and proposes specific reform measures according to relevant issues, in order to effectively improve the overall teaching level of vocal music courses in college music performance and promote students' all-round development.

\section{Introduction}

With the improvement of school conditions and the demand for music performance talents, many colleges have established music performance majors on the basis of musicology. However, the current situation of teaching and training is not optimistic, resulting in the improvement of teaching quality. There is a big disconnect from social needs, which seriously dampens students' enthusiasm for learning. Therefore, it is extremely urgent to fully understand the current situation of vocal music teaching in college music performance majors and actively explore the vocal music teaching mode of college music performance majors that meet the development requirements of the times ${ }^{[1]}$.

\section{The present situation of vocal music teaching in college music performance}

\subsection{Students have a poor professional foundation}

In recent years, with the continuous expansion of colleges and universities, the number of candidates for art examinations has increased year by year. Some colleges and universities have reduced the professional requirements in order to complete the enrollment goals. The students are inconsistent, some students have poor professional foundations, weak professional theories, and low level of cultural knowledge.

\subsection{Limited time allocation for professional hours}

Most of the college music performance students will take the major course in the professional 
class, and arrange the corresponding class according to the students' own ability level, but generally it will not exceed 1 section/week. However, other public classes account for a relatively large proportion, such as English, politics, and sports. The students themselves have a poor foundation and they do not have enough time to study. The teaching effect will inevitably be greatly reduced, and they will not meet the training objectives of the music performance profession.

\subsection{Vocal teaching method is traditional, single}

At present, in the vocal music teaching method, the classroom teaching in the form of "one-on-one" or "one-on-three" is basically adopted. As shown in Figure 1, this teaching method pays more attention to the training of vocal skills, and some teaching of theoretical knowledge and The cultivation of other abilities will be ignored due to time constraints. In the teaching of this model, the learning limitations of students are relatively large, and there is no object to be compared for comparison. It is difficult to form a learning atmosphere that encourages each other, brainstorms and improves together ${ }^{[2]}$.

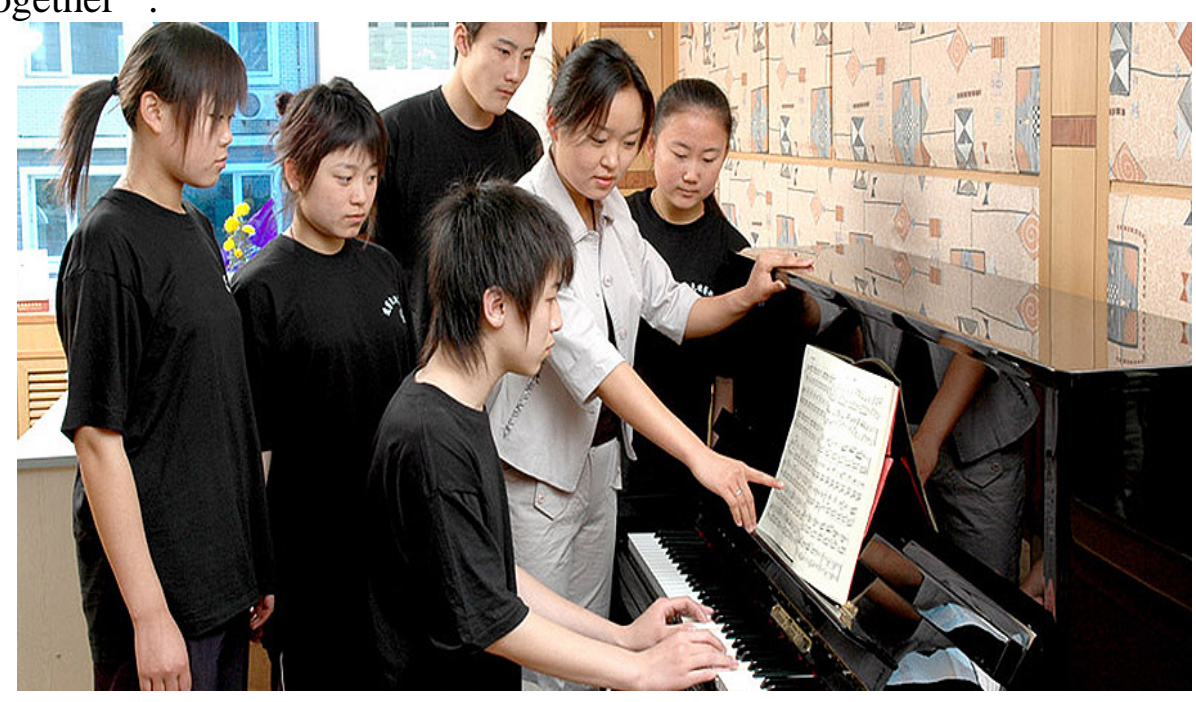

Figure 1 Traditional vocal teaching mode

\subsection{Music performance professional teacher is weak}

In recent years, some colleges and universities have significantly expanded their enrollment, but the corresponding faculty has not kept up with the growth of students. Due to the particularity of the music performance profession and the different training objectives, professional music performance talents are needed. At present, many teachers engaged in performance teaching are still teachers of music music teaching. In this way, the teaching of music performance students must be influenced by the goal of musicology training, which is not conducive to the improvement and development of students' abilities.

\subsection{There are not many opportunities for professional internship practice}

In the setting of vocal music teaching in college music performance, most of the arrangements are pure vocal classroom teaching, lacking teaching guidance for students' stage practice and social practice. In the four years of university study, only a few weeks of social practice internships will be arranged in the fourth year of school. Some institutions lack effective organization and supervision of internships, and even allow students to contact the internship units themselves, so that the students' practical ability cannot be truly After getting exercise, the practice of internship 
loses its own role and effect.

\section{The reform of vocal music teaching in college music performance major}

\subsection{Improve students' musical perception}

In order to improve students' overall vocal performance, teachers need to continuously combine cultural curriculum knowledge to teach, and enhance their cultural literacy to enhance their perception of music. First of all, strengthening students' cultural knowledge can better enable them to change their existing thinking more quickly and adapt to new requirements when faced with the requirements that many schools have not taught. This is also the additional ability for students. A culture path. In order to achieve this goal, the school needs to incorporate more cultural courses and art courses in the teaching process to enhance their cultural literacy, so that students can produce more about how to sing vocal works. Ideas, in order to more systematically form their own understanding of vocal music teaching, better understand the rich emotions and meanings hidden in the vocal music class ${ }^{[3]}$.

\subsection{Improve traditional teaching methods}

The overall teaching goal is an innovative teaching initiative, so the corresponding teaching methods should be continuously upgraded and improved to meet the overall teaching objectives. Therefore, in the process of teaching, teachers should appropriately improve and update the teaching methods according to the differences in their physical and psychological qualities. For example, it is possible to appropriately use online teaching resources and modern teaching methods to display the content to be taught in video, pictures, etc., to more intuitively show what expressions and limbs should be used in different vocal works. To sing in terms of timbre, it is also necessary to use the Internet to teach more vocal singing methods with more international standards, and finally achieve better teaching results.

Another important point is to realize the transformation of the classroom "role, relationship". A variety of teaching modes are used to mobilize the enthusiasm of interaction between students and teachers, so that students can continue to be developed and self-excavated, and finally, the literacy of the students in the vocal music course can be improved. Figure 2 shows the situation of students learning vocal music after improving the traditional teaching mode.

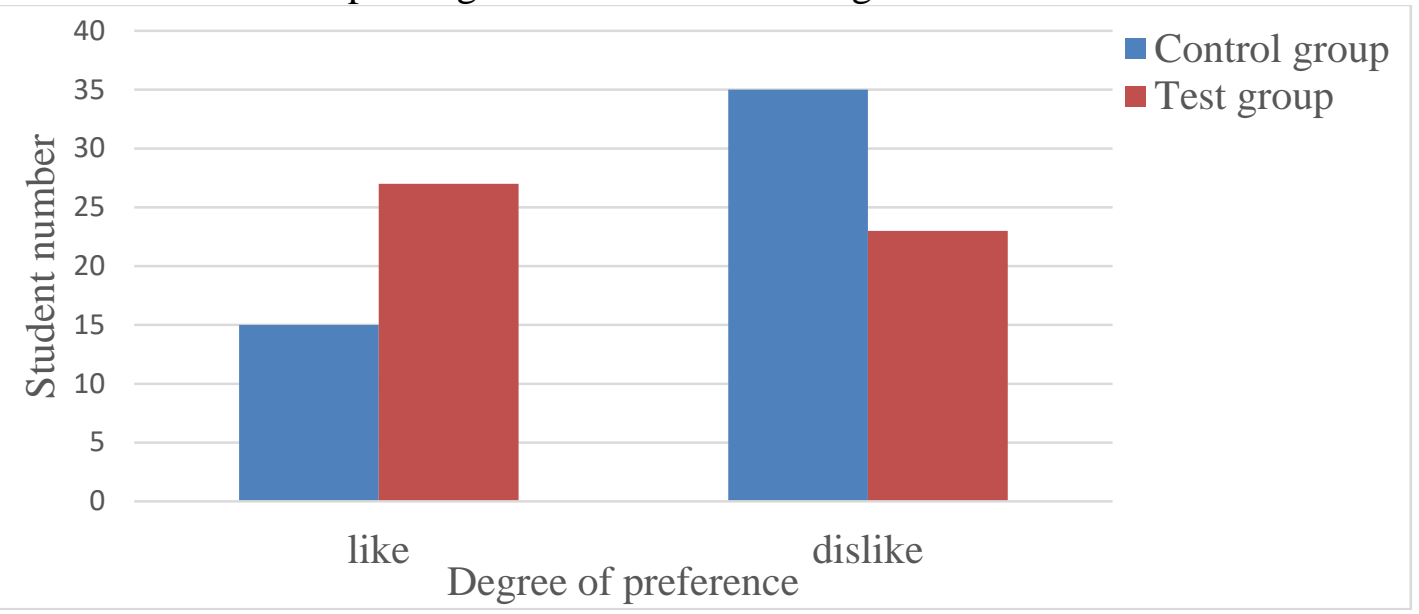

Figure 2 The effect of student learning after the reform of acoustics teaching 


\subsection{Improve teachers' own literacy}

From the perspective of modern vocal music teaching, improving the quality of teaching should start with teachers. In the process of cultivating students, higher art colleges should adapt to the needs of modern teaching, adjust the forms of multi-angle teaching, and finally complete the teaching tasks effectively. All of this is based on the improvement of teachers' comprehensive quality. In order to improve the quality of teachers, we should start from two aspects: first, to enhance teachers' teaching ability, and second, to enhance teachers' ability to learn and innovate. Colleges and universities can use the "please come in, go out" way, on the one hand, plan to send teachers out to study related professional courses, on the other hand, you can hire experts and scholars from outside to conduct regular training for teachers. At the same time, colleges and universities can also carry out mutual learning between teachers and exchange teaching progress of different courses. These all contribute to the improvement of teachers' self-learning ability. Teachers should keep pace with the times and constantly improve their business capabilities through self-improvement. It can be said that in the teaching process, teachers are role models for students and have a leading role. The improvement of teachers' personal abilities will help to better develop a variety of vocal classroom teaching ${ }^{[4]}$.

\subsection{Strengthening the practice of stage practical teaching and social practice teaching}

The current society's practical ability requirements for music talents are relatively high. Therefore, it is important to improve the practical ability of music students. In music teaching activities, music theory teaching is an important teaching content, and practical teaching is also an important teaching content. As a practical technical course, vocal music courses need to be reflected in stage practice and social practice. By guiding students to participate in stage practice and social practice, teachers can help students to consolidate the theoretical knowledge of learning, and also cultivate students' practical ability and stimulate students' creativity. Colleges and universities should pay attention to stage practice and social practice, and provide students with some practical opportunities. For example, students can be encouraged to participate in local music and cultural activities and various practical activities, and they can continuously improve their practical ability in social integration. Teachers can instruct students to perform vocal performances in a combination of ways, exercise their actual performance skills, and also allow students to evaluate each other's performances so that students can discover their own deficiencies and improve their ability to solve problems $^{[5]}$.

\section{Conclusions}

In general, integral teaching is the main teaching direction of music performance professional vocal music course now and in the future. Effectively improving the overall teaching level of vocal music courses in college music performances can not only promote students' all-round development, but also enhance students' artistic appreciation ability. Therefore, the teaching process of colleges and universities must constantly explore and innovate in teaching methods and teaching forms, improve teaching quality, and strive to cultivate applied music and art talents that meet the needs of society.

\section{References}

[1] Zhai Xiaolan. Thoughts on the Short Semester Course of Vocal Music in College Music Performance [J]. , (2013):35-36.

[2] Cai Zhicuo. Reform and Innovation of Vocal Music Teaching Mode in College Music Performance [J]. Northern 
Music, 2017, 37(14): 131-132.

[3] Zhou Qin. Innovation and Thinking of Vocal Music Reform in Music Performance of Local Universities [J]. Journal of Oriental Collection, 2018(1).

[4] Liu Yanjiao. Problems and Countermeasures of Vocal Music Teaching in Music Performance in Colleges and Universities [J]. Popular Songs, 2016(10).

[5] Jiang Lan. Research on the teaching of vocal performance in colleges and universities [D]. Sichuan Conservatory of Music, 2015. 